\title{
Comparative characteristics of elite New Zealand and South African u/16 rugby players with reference to game- specific skills, physical abilities and anthropometric data
}

\author{
Emanuel J Spamer (PhD) ${ }^{1}$ \\ Daniël $\mathbf{J}$ du Plessis (MEd) ${ }^{2}$ \\ Ernst H Kruger (PhD) ${ }^{2}$ \\ ${ }^{1}$ North-West University, Private Bag X6001, School of Continuous Teacher Education, North-West University, Potchefstroom \\ ${ }^{2}$ Department of Biokinetics, Sport and Leisure Sciences, University of Pretoria
}

\begin{abstract}
Objective. A comparative study of elite New Zealand and South African $\mathrm{u} / 16$ rugby players with special reference to game-specific skills, physical abilities and anthropometric data.

Design and settings. A battery of tests was used to obtain information concerning a group of elite New Zealand players $(N=24)$ and two elite South African groups $(N=64)$. Information was obtained for game-specific skills, physical abilities, and anthropometric data.

Results. The New Zealand players outperformed the South African players in game-specific tests, physical abilities, and anthropometric measurements. Where the South African groups performed better than the New Zealand group, it was not practically significant.

Conclusion. South African rugby authorities should be cognisant of the areas where South African $\mathrm{u} / 16$ rugby players were outperformed by their New Zealand counterparts, and consequently develop specific development programmes to address these shortcomings.
\end{abstract}

\section{Introduction}

The need for talent identification in sport has developed into a science. According to Singer et al. ${ }^{1}$ talent identification in sport aims to predict future achievements based on the present abilities and potential of a sportsperson. Most of the game-specific skills, anthropometric measurements and physical/motor abilities, including speed, strength, power and agility, change in young sportsmen during their development years $\left(8-18\right.$ years of age) ${ }^{2}$

\section{CORRESPONDENCE:}

Professor E J Spamer

Director, School for Continuing Teachers' Education

North-West University

Potchefstroom 2520

South Africa

E-mail: Manie.Spamer@nwu.ac.za
Considering the sport of rugby, the limited number of years during which a rugby player is able to play elite rugby have necessitated the early identification of potential rugby talent, as well as ways and means to improve the performance of rugby players from an early age. ${ }^{2}$ The lack of knowledge in this regard as well as the non-availability of comparative data between countries, are limiting factors. Comparisons of elite rugby players in top rugby-playing nations such as South Africa, New Zealand, the UK and Australia, may assist coaches and sport scientists to identify talented rugby players at a younger age, and to develop these players to a higher international standard. However, these types of studies are limited. Besides a comparative study between South African and British rugby youth, ${ }^{3}$ and a comparative study between 12-year-old New Zealand and South African rugby players, ${ }^{4}$ no other published studies comparing international rugby players could be found. The fact that South Africa and New Zealand are currently voted number one and two in the world of rugby makes for an interesting comparison of their elite youth rugby players.

The purpose of this investigation was to conduct such a comparative study between elite $u / 16$ rugby players of these two nations. The main aim was to provide information regarding the physical profile of $u / 16$ rugby players and hopefully to stimulate future research on talent identification and development.

\section{Methods}

Three groups of elite $\mathrm{u} / 16$ rugby players from New Zealand and South Africa participated in this study. For the purpose of this investigation the term 'elite rugby players' refers to $\mathrm{u} / 16$ rugby players who played provincial rugby at school level. The first study group comprised 24 members of the Taranaki Provincial u/16 A rugby team in New Zealand, ${ }^{5}$ the second group comprised $43 \mathrm{u} / 16$ elite high-school rugby players in the North-West Province in South Africa, ${ }^{6}$ and the third group comprised $21 \mathrm{u} / 16$ rugby players in the North-West Province competing in the national tournament. ${ }^{7}$ The first study group was tested during the mid-rugby season of 2004 in New Zealand. ${ }^{5}$ The second study group was tested during the rugby season of $1996^{6}$ and the third study group was tested during the mid-rugby season of $2002 .^{7}$ The test protocol consisted of anthropometric measurements, rugby-specific skill tests, and physical and motor ability tests. The detailed descriptions of the battery of tests executed can be found in the relevant references; however, the aims of the different tests will be described in short. 


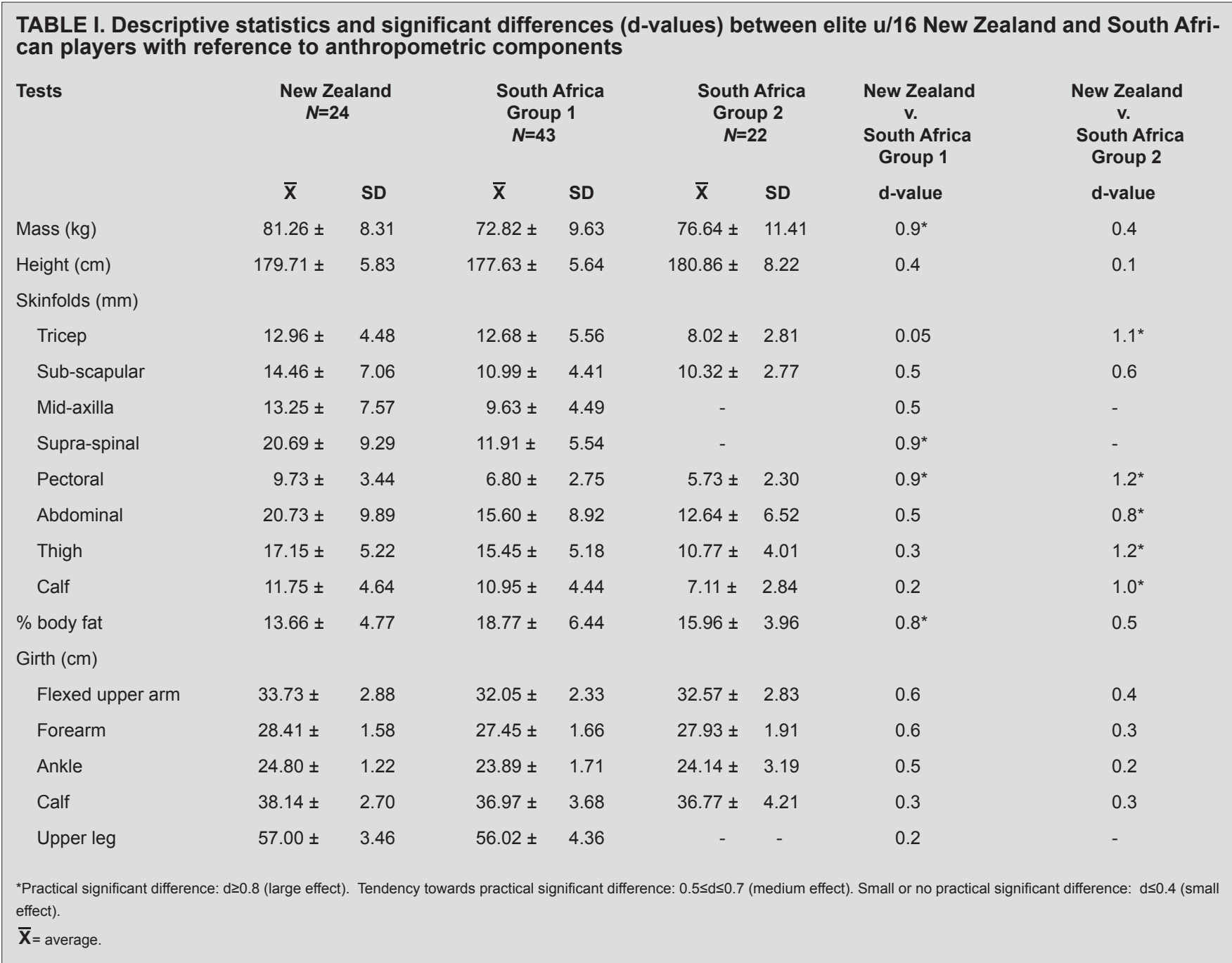

TABLE II. Descriptive statistics and significant differences (d-values) between elite u/16 New Zealand and South African players with reference to physical and motor abilities

\begin{tabular}{|c|c|c|c|c|c|c|c|c|}
\hline \multirow[t]{2}{*}{ Tests } & \multicolumn{2}{|c|}{$\begin{array}{l}\text { New Zealand } \\
\quad N=24\end{array}$} & \multicolumn{2}{|c|}{$\begin{array}{l}\text { South Africa } \\
\text { Group } 1 \\
N=43\end{array}$} & \multicolumn{2}{|c|}{$\begin{array}{c}\text { South Africa } \\
\text { Group } 2 \\
N=22\end{array}$} & \multirow{2}{*}{$\begin{array}{c}\text { New Zealand } \\
\text { v. } \\
\text { South Africa } \\
\text { Group } 1 \\
\text { d-value }\end{array}$} & \multirow{2}{*}{$\begin{array}{c}\text { New Zealand } \\
\text { v. } \\
\text { South Africa } \\
\text { Group } 2 \\
\text { d-value }\end{array}$} \\
\hline & $\bar{x}$ & SD & $\overline{\mathbf{x}}$ & SD & $\bar{x}$ & SD & & \\
\hline Sit and reach $(\mathrm{cm})$ & $-2.21 \pm$ & 8.75 & $2.36 \pm$ & 2.30 & $5.91 \pm$ & 6.80 & 0.02 & $0.9^{*}$ \\
\hline Vertical jump (cm) & $50.07 \pm$ & 7.00 & $47.16 \pm$ & 6.11 & $40.55 \pm$ & 10.67 & 0.3 & $0.9^{*}$ \\
\hline Speed endurance (\%) & $5.38 \pm$ & 1.48 & $6.37 \pm$ & 3.15 & $6.58 \pm$ & 3.21 & 0.3 & 0.4 \\
\hline Zig-zag run (s) & $6.65 \pm$ & 0.44 & $7.16 \pm$ & 0.48 & - & - & $1.1^{*}$ & \\
\hline Speed $10 \mathrm{~m}(\mathrm{~s})$ & $1.79 \pm$ & 0.09 & - & - & $1.89 \pm$ & 0.20 & - & 0.5 \\
\hline Speed $45.7 \mathrm{~m}$ (s) & $6.21 \pm$ & 0.38 & $6.61 \pm$ & 0.34 & - & - & $1.1^{*}$ & \\
\hline Flexed arm hang (s) & $38.63 \pm$ & 16.17 & - & - & $26.03 \pm$ & 12.04 & - & $0.8^{*}$ \\
\hline \multicolumn{9}{|c|}{$\begin{array}{l}\text { *Practical significant difference: } d \geq 0.8 \text { (large effect). Tendency towards practical significant difference: } 0.5 \leq d \leq 0.7 \text { (medium effect). } \\
\text { effect). }\end{array}$} \\
\hline
\end{tabular}

\section{Anthropometric tests}

Standard measurements were performed for body composition. These included body mass, stature, skinfolds (triceps, subscapular, mid-axilliary, pectoral, supraspinal, abdominal, thigh and calf skinfold for prediction of body fat and sum of skinfolds), and girths (flexed upper arm, forearm, thigh, calf and ankle). ${ }^{8}$ 


\begin{tabular}{|c|c|c|c|c|c|c|c|c|}
\hline \multirow[t]{2}{*}{ Tests } & \multicolumn{2}{|c|}{$\begin{array}{l}\text { New Zealand } \\
\quad N=24\end{array}$} & \multicolumn{2}{|c|}{$\begin{array}{l}\text { South Africa } \\
\text { Group } 1 \\
N=43\end{array}$} & \multicolumn{2}{|c|}{$\begin{array}{c}\text { South Africa } \\
\text { Group } 2 \\
N=22\end{array}$} & \multirow{2}{*}{$\begin{array}{c}\text { New Zealand } \\
\text { v. } \\
\text { South Africa } \\
\text { Group } 1 \\
\text { d-value }\end{array}$} & \multirow{2}{*}{$\begin{array}{c}\text { New Zealand } \\
\text { v. } \\
\text { South Africa } \\
\text { Group } 2 \\
\text { d-value }\end{array}$} \\
\hline & $\bar{x}$ & SD & $\overline{\mathbf{x}}$ & SD & $\bar{x}$ & SD & & \\
\hline Ground skills (s) & $3.27 \pm$ & 0.22 & $5.68 \pm$ & 0.36 & $3.62 \pm$ & 0.25 & $6.7^{*}$ & $1.4^{*}$ \\
\hline Side steps $(/ 10)$ & $5.96 \pm$ & 2.46 & $4.46 \pm$ & 1.35 & $5.50 \pm$ & 1.40 & 0.6 & 0.2 \\
\hline Air and ground kicks $(/ 10)$ & $7.13 \pm$ & 1.92 & $4.60 \pm$ & 1.90 & $5.19 \pm$ & 0.93 & $1.3^{*}$ & $1.0^{*}$ \\
\hline Passing distance $(\mathrm{m})$ & $21.96 \pm$ & 2.71 & $19.95 \pm$ & 3.27 & $21.14 \pm$ & 4.34 & 0.6 & 0.2 \\
\hline $\begin{array}{l}\text { Passing accuracy } \\
\text { over } 4 \mathrm{~m}(/ 10)\end{array}$ & $3.83 \pm$ & 1.88 & $4.23 \pm$ & 2.36 & $4.50 \pm$ & 2.28 & 0.1 & 0.3 \\
\hline $\begin{array}{l}\text { Passing accuracy } \\
\text { over } 7 \mathrm{~m}(/ 30)\end{array}$ & $24.42 \pm$ & 3.12 & $25.69 \pm$ & 2.57 & $23.55 \pm$ & 5.76 & 0.4 & 0.2 \\
\hline Kicking distance $(\mathrm{m})$ & $40.90 \pm$ & 4.60 & $38.02 \pm$ & 6.56 & $41.41 \pm$ & 11.13 & 0.4 & 0.04 \\
\hline Kick-off distance (m) & $37.59 \pm$ & 4.37 & $36.07 \pm$ & 7.80 & $33.60 \pm$ & 9.18 & 0.2 & 0.4 \\
\hline \multicolumn{9}{|c|}{$\begin{array}{l}\text { *Practical significant difference: } d \geq 0.8 \text { (large effect). Tendency towards practical significant difference: } 0.5 \leq d \leq 0.7 \text { (medium effect). Small or no practical significant difference: } d \leq 0.4 \text { (sm } \\
\text { effect). }\end{array}$} \\
\hline
\end{tabular}

\section{Physical and motor ability tests}

These included the sprinting test (done over $45.7 \mathrm{~m}$ to assess the speed ability of the players ${ }^{9}$ ), the explosive power test (vertical jump test to assess explosive power strength ${ }^{10}$ ), the flexibility test (adapted sit-and-reach test to assess flexibility in the lower back and hamstrings ${ }^{10}$ ), the agility test (zig-zag run over $24 \mathrm{~m}$ to assess agility and speed running ${ }^{9}$ ), the speed endurance test (also known as the test of Hazaldine and $\mathrm{McNab}^{11}$ in which the players did a number of sprints with 20-second rest periods to assess speed endurance ability), and the flexed arm hang (hanging on a horizontal bar to assess upper body muscle endurance. ${ }^{2}$

\section{Game-specific skills tests}

These tests included passing for accuracy (while the rugby player is jogging he passes a ball through a circle $4 \mathrm{~m}$ away to assess the passing accuracy to his right and left ${ }^{2}$ and another accuracy passing test over $7 \mathrm{~m}$ with the player not moving ${ }^{9}$ ), passing for distance (the player attempts to pass a rugby ball to a standing partner to assess distance of passing), ground skills test (while running the player picks the ball up, runs around a marker, and places the ball where it was picked up, to assess ground skill while running ${ }^{12}$ ), kicking for distance (the player takes the ball in both hands and kicks the ball as far as possible to assess kicking distance; place-kicking using a tee, with an unlimited approach, was also used for the same test $^{9}$ ), air and ground kicking ability (the rugby player performed a chip, followed by a grubber with both feet to assess both skills ${ }^{12}$ ), and side-step ability (carrying the ball in both hands, running through obstacles and side-stepping to the left and right to assess the ability to dodge ${ }^{13}$ ).

These anthropometric, physical and motor abilities and rugby game-specific tests have been used by several researchers in the field of talent identification in rugby. ${ }^{2,3,6,7}$ It must be acknowledged that some of the tests favour certain rugby-specific positions and this should be taken into account for talent identification. Another point to note is that the battery of tests used for the three sampling groups was spread over time and the researchers in each study did not always use the full battery of tests. In a few of the tests the New
Zealand players were only compared with one of the South African groups instead of both groups, due to the fact that the two South African groups did not perform the same battery of tests. The three studies referred to in this paper form part of an international project (South Africa, New Zealand and England) on talent identification among young rugby players, and were managed from the North-West University. The facilitators who conducted the tests were all trained by the same research team to ensure that the test procedures were identical in all three studies.

\section{Order of testing}

Anthropometric and flexibility measurements were investigated first. The rugby players did a general warm-up consisting of jogging and stretching of all major muscle groups, as well as short sprints. All the physical, motor and rugby-specific tests were done on a rotation basis. The speed endurance test was conducted last, after the players had been allowed sufficient rest.

\section{Statistics}

Data of all the groups were analysed with the SAS computer software programme. ${ }^{14}$ Descriptive statistics (means and standard deviation) were annotated. Because of the relatively small size and nature of the study groups (convenience sampling), d-values (effect sizes) were calculated to determine practical significant differences between the New Zealand and South African groups. ${ }^{15}$

\section{Results}

\section{Anthropometric data}

Table I shows that the eight skinfold measurements (averages) obtained for the NZ group, were all higher than the same skinfold measures of both SA groups. Practical significant differences (large effect size) were found between the $\mathrm{NZ}$ and $\mathrm{SA}_{1}$ groups with regard to the supra-spinal $(d=0.9)$ and pectoral $(d=0.9)$ skinfolds; and between the $N Z$ and $S A_{2}$ groups with regard to tricep $(d=1.1)$, pectoral $(d=1.2)$, abdominal $(d=0.8)$, thigh $(d=1.2)$, and calf $(d=1.0)$ skinfolds. Table I shows that NZ also scored higher in the following girth meas- 
urements: flexed upper arm, forearm, ankle, calf and upper leg. The NZ players in this study were heavier than the SA groups, but slightly shorter than $\mathrm{SA}_{2}$. A tendency towards practical significant differences (medium effect size) was found between the $\mathrm{NZ}$ and $\mathrm{SA}_{1}$ groups in the flexed upper arm $(d=0.6)$, forearm $(d=0.6)$ and ankle $(d=0.5)$ girth measurements.

\section{Physical and motor abilities}

Table II shows that the NZ group performed better than both SA groups in six of the seven tests for physical and motor abilities. The only physical and motor test in which the SA groups performed significantly better than the New Zealand group, was in the sit-andreach test. Large practical significant values were found between the $\mathrm{NZ}$ group and the $\mathrm{SA}_{1}$ group in the zig-zag run $(\mathrm{d}=1.0)$ and the $45.7 \mathrm{~m}$ speed test $(\mathrm{d}=1.1)$; the times of the $\mathrm{NZ}$ group were faster in both tests. Practical significant differences were found between the $\mathrm{NZ}$ and $\mathrm{SA}_{2}$ groups in the sit-and-reach $(\mathrm{d}=0.9)$, vertical jump $(d=0.9)$, and flexed arm hang tests $(d=0.8)$. No practical significant differences (small effect size) were found in the speed endurance test $\left(S_{1}: d=0.3 ; S A_{2}: d=0.4\right)$. A tendency towards practical significant difference (medium effect) was found in the speed over $10 \mathrm{~m}$ test $\left(\mathrm{SA}_{2}: \mathrm{d}=0.5\right)$

\section{Game-specific skills}

Table III shows that the NZ group outperformed their SA counterparts in six of the eight tests. The results show practical significant differences (large effect size) between the NZ and both the SA groups in only two of the eight game-specific skill tests, namely: ground skills ( $N Z$ v. $S A_{1}: d=6.7$; and $N Z$ v. $S A_{2}: d=1.4$ ) and air and ground kicks ( $N Z$ v. $S A_{1}$ : $d=1.3$; and $N Z$ v. $S A_{2}: d=1.0$ ). The $S A$ groups performed better than the NZ group in passing for accuracy over $4 \mathrm{~m}$, but only with a small practical significance $(d=0.3)$. In three tests, i.e. ground skills, ground kicks and kick-off distance, the NZ group outperformed both SA groups.

\section{Discussion}

This study found that NZ elite $\mathrm{u} / 16$ rugby players performed better than SA players in the anthropometric tests, physical and motor abilities tests and game-specific tests. In cases where the SA groups had higher scores than the NZ group, the practical significant differences were low and therefore of questionable value. In particular, the NZ players were heavier with larger girth measurements. In addition, the NZ players were quicker than the SA players, possibly as a result of the superior explosive power (vertical jump test). ${ }^{16}$ In the zig-zag run test, where speed plays an important role, the NZ group also had quicker times than the SA group. Pienaar and Spamer ${ }^{2}$ found that younger rugby players' strength is not as developed as expected, which may be the reason for the poor performance of the two SA groups in this specific test component. A lack of compulsory physical education at South African schools may be a reason for this disadvantage. Ethnicity may be a factor in the strength test, where Maori, Tongan and Samoan rugby players develop earlier than their SA counterparts. 5

For the speed endurance test, where the NZ group had the best test values, a factor that might have played a role was the fact that the NZ group was tested at sea level, whereas the SA group was tested at high altitude (North-West Province). Anaerobic performance times are longer (poorer performance) at higher elevations, than at sea level. ${ }^{17}$
With regard to game-specific skills, the NZ group scored better in the kicking for distance, passing for distance, and kick-off for distance tests. This may be due to the fact that the NZ group possesses more power (vertical jump), strength (flexed arm hang), and longer limbs (height). All these factors may have contributed to the NZ players being able to kick and pass the ball further than the SA group. However, where accuracy was the determinant factor (passing for accuracy over $4 \mathrm{~m}$ and $7 \mathrm{~m}$ ), the SA groups had better test values. In rugby, the above factors play an important role in talent identification, position development, and the selection of players for a team. If rugby players obtain the above average scores they show potential talent. $^{2}$

There may be a number of reasons why the NZ group scored better in the game-specific skills. One reason is that New Zealanders play rugby and take part in rugby development programmes from a very young age (4 years), compared with South Africans, who start playing rugby at a later age (8 years). Although morning grade (Bulletjie) rugby started in the late nineties in South Africa, this had no effect on the SA groups tested in this study. Thus, it may be estimated that the NZ group played rugby and participated in rugby clinics for an average of 4 years longer than the SA groups, which means that they had more time to develop their rugby-specific skills. Another possible reason is that the NZ and SA groups were tested approximately 7 years apart. The practical significant differences between the two SA groups were also found in the game-specific skills tests that were tested about 6 years apart (Van Gent tested in $2003^{7}$ ). The elapsed time period between the test dates would have affected the scores of the game-specific skills. For example, the rugby ball would have travelled further distances as a result of technological development and training and coaching techniques would also have improved over this time.

The NZ group scored better in the side-step and air-and-ground skill tests. A number of factors could have played a role in this finding. For example, the NZ group scored better in the speed and zig-zag run tests, therefore they are able to run themselves into better position to recollect the ball in the air-and-ground skill test, and performed better in the side-step test. However, this result should be interpreted with caution as the same tester did not administer the testing for both the NZ and SA groups. The relatively low interrater reliability could have contributed to the difference in the scores of these tests. ${ }^{18}$

In conclusion, South African rugby authorities should take cognisance of the areas where South African $u / 16$ rugby players were outperformed by their New Zealand counterparts, and consequently develop specific development programmes to address these shortcomings.

\section{REFERENCES}

1. Singer RN, Murphy M, Tennant LK. Handbook of research on sport psychology. New York: Macmillan; 1993.

2. Pienaar AE, Spamer EJ. A longitudinal study of talented young rugby players as regards their rugby skills, physical and motor abilities and anthropometrical data. J Hum Mov Stud 1998;34:13-32.

3. Spamer EJ, Winsley R. Comparative characteristics of elite English and South African 18-year-old rugby-players with reference to game-specific skills, physical abilities and anthropometrical data. J Hum Mov Stud 2003;45:187-196

4. Van der Westhuizen D, Winders J, Dreyer L, Spamer EJ, eds. Anthropometric, game-specific, physical and motor ability variables of 12 -year old rugby players (New Zealand and South Africa). Presentation delivered at the 2004 Sport Conference; 2004; Brisbane.

5. Du Plessis DJ. Comparative characteristics of elite New Zealand and South African u/16 rugby-players with reference to game-specific skills, physical abilities and anthropometric data. Masters Dissertation in Movement Education. Pretoria: University of Pretoria; 2007. 
6. Hare E. Die identifisering van rugbytalent by seuns in die senior sekondêre skoolfase (The identification of rugby talent in boys in the senio secondary school phase). MEd Dissertation in Afrikaans: Potchefstroom University for Christian Higher Education; 1997.

7. Van Gent MM. A test battery for determination of positional requirements in adolescent rugby players. Masters Dissertation: Potchefstroom University for Christian Higher Education; 2003.

8. Norton KI, Olds TS, Olive SC, Craig NP. Anthropometry and sport performance. In: Norton KI, Olds S, eds. Anthropometrica: a textbook of body measurements for sports and health courses. Sidney: UNSW Press; 1996. p. 287-364.

9. American Alliance for Health Physical Education and Recreation (AAH PER). AAHPER skills test manual for football. Washington: AAHPER; 1966

10. Thomas JR, Nelson JK. Introduction to research in health, physical education, recreation and dance. Campaign: Human Kinetics; 1985.
11. Hazaldine R, McNab T. Fit for rugby. London: Kingswood Press; 1991.

12. Australian Rugby Football Union. Australian rugby skills test. Sydney: Australian Rugby Football Union; 1990.

13. Cooke G. Rugby Union. London: Black; 1984.

14. SAS Institute. SAS/STAT user's guide statistics. Cary: SAS Institute; 1991.

15. Cohen J. Statistical power analysis for behavioural sciences. Hillsdale: Erlbaim; 1988.

16. Foran B. High-performance sports conditioning. London: Human Kinetics; 2001.

17. McArdle WD, Katch FI, Katch VI. Exercise physiology. Lippincott: Williams \& Wilkins Publishers; 2001.

18. Baechle TR, Earle RW. Essentials of strength training and conditioning Champaign: Human Kinetics; 2000. 